\title{
THE CO.TR.I.S SYSTEM: TOWARDS A SMARTER COASTAL TRANSPORT NETWORK FOR SMART ISLANDS
}

\author{
V. Moussas ${ }^{1,3, *}$, D. N. Pantazis ${ }^{2,3}$, P. Stratakis ${ }^{2,3}$ \\ ${ }^{1}$ Dept. of Civil Engineering, University of West Attica Athens, Greece - vmouss@ teiath.gr \\ ${ }^{2}$ Dept. of Survey \& Geoinformatics Engineering, University of West Attica Athens, Greece - (dnpantazis, pstratak)@ teiath.gr \\ ${ }^{3}$ SOCRATES Research Laboratory, University of West Attica Athens, Greece - http://socrates.stef.teiath.gr
}

KEY WORDS: Co.Tr.I.S, Coastal Network, Transportation, Optimization, ICT, Mobility, Smart Cities, Smart Islands

\begin{abstract}
:
The Coastal Transport Information System (Co.Tr.I.S) is a multifunction information system that is developed for the effective design of coastal transportation lines. The system incorporates several subsystems which include the models, tools, and techniques that support the design of improved coastal networks. Co.Tr.I.S main aim is to support any decision making process of the involved players (Ministry, Maritime companies, Local Authorities, Travel Agencies, Passengers, etc) regarding the improvement \& the optimal use of a coastal transport network. Co.Tr.I.S data retrieval, analysis, visualization, network design \& decision support can accelerate the very slow (currently annual in Aegean) rate of coastal transport network update/upgrade procedures, and, create smarter network implementations that may adapt online on the various demand or requirement changes or updates. Connections, transportation, mobility, as well as port automation are some of the key factors for the "smartification" of entire islands especially in an archipelago like the Aegean Sea. In this work, we present the network design optimization functionality of Co.Tr.I.S, the various optimization stages, the Genetic Algorithm (GA) implementations and its potential to propose a better network design based on each user preferences. A sample case study is given to show its smartness \& adaptability to each user needs and, finally, a discussion follows on how it could be complemented by emerging smart technologies for smarter islands.
\end{abstract}

\section{INTRODUCTION}

The term "smart city" is widely used in our days. The concept is something relatively new in the scientific literature. It has emerged, the last two decades (Albino et al., 2015) and it deals mostly with the economic and social aspects of a city in a sustainable urban environment (Winters, 2011; Manville et al., 2014) and it is sometimes identical with everything that has to do with ICT applications, networks, transportation and generally technological implementations. A smart city is further improved by also becoming a "green city" or a sustainable city, or eco-city, where smartness is also used for better use of resources, minimum waste, pollution \& environmental impact and sustainability. Following "smart cities" the term "smart islands" appeared in the project "Smart Web services for Mediterranean Islands" (GISIG, 2014), and is spreading, especially in countries with many islands. In our case, the term "smart sustainable island" has the same meaning as the term smart sustainable city, but in addition: 1) it refers to the entire region of an island and not to a specific city, and, 2) the term "sustainable" means that the entire island follows all the good practices to preserve the sustainable development and the protection of the environment, natural and urban, including the cultural heritage in a holistic and integrated manner. The particularities of the "smartification" of an island are related to its geographic characteristics, the isolation, the coastal lines, the tourism, the infrastructure, the transport of goods, the medical care, the education, the limited economic possibilities, etc. (Pantazis, 2017)

Following the EU initiative "smart island", the key factors are energy, transport, water, waste, governance, ICT, and economy.
Some 'special key factors' may be added in some islands, e.g., refugees. Various actions required to satisfy each factor. For example, regarding Energy, "smarter" means to improve performance, reliability, controllability, and, moving to a smarter grid that will reduce emissions. This can be done by allowing greater integration of renewable resources, more efficient use of the energy they produce, the integration of smart vehicles and promotion of cleaner transport and the introduction of demand response mechanisms to reduce energy demand. In our case, we will focus on the Transport key factor for smarter sustainable islands. From the three possible means of transportation (air, land, sea) the sea/surface is the one that distinguishes islands from a typical continental city. A special tool is therefore required for the improvement of the coastal transport networks either between islands or to the mainland. The Co.Tr.I.S system is a promising candidate for this role, provided its wider adoption by the appropriate authorities and stakeholders. (Pantazis, 2013)

\section{CO.TR.I.S SYSTEM GENERAL DESCRIPTION}

Co.Tr.I.S is an integrated spatial information system developed to contribute to a more effective design of coastal transport lines in the Aegean Sea, Greece. Nevertheless, Co.Tr.I.S may be applied to any maritime environment and for any type of maritime transport. This fundamental and applied research project financed by the EU and the Greek government was completed in October 2015. Today, Co.Tr.I.S further development continues partially funded by the University of West Attica and by the SOCRATES Research Laboratory at the University of West Attica.

* Corresponding author 
The system is based on Geographic Information System (GIS) software, add-on traffic management and other applications (mapping, statistics, design of new coastal lines etc.), divided in various subsystems for, coastal lines design proposals, spatial queries concerning the coastal transport network, statistics, thematic maps, graphs production, etc. The fundamental and most challenging requirements for Co.Tr.I.S were the capability for proposals and "construction" of a) new coastal lines, b) modification of existing ones c) new entire coastal networks, based on user preferences and available data such as ports, nodes, coastal lines, passengers demand, distances, airports, ships/fleet, islands population, etc.

The system's users supported are currently divided into four main categories (groups). Each group may use a slightly different version of the application that is adjusted for their needs. The main users are the Ministry of Marine and Aegean (Policymakers), Local Authorities and the local population, Ship-owners union and Coastal lines companies, and the Travel Agencies or potential Passengers/Tourists.

Co.Tr.I.S contribution to smarter and more sustainable coastal transport network is multi-fold. In the following sections, we present the functionality of its design optimization (S6) subsystem and its potential contribution to optimize existing situations. In addition, we investigate its collaboration with other smart technologies such as smart ports or USVs in order to unleash its real-time online potential. The role of the optimization tools in Co.Tr.I.S and the overall workflow is depicted in Figure 1. (Moussas, 2015)

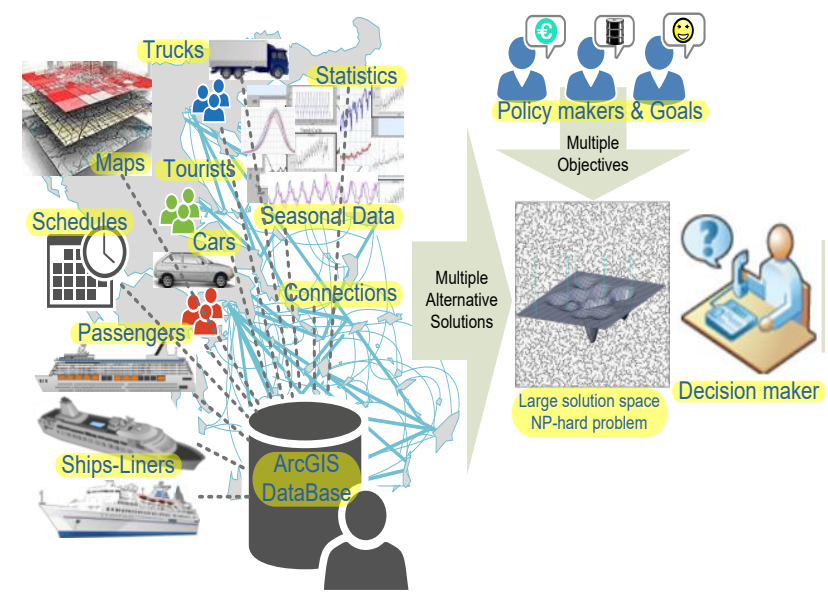

Figure 1. Schematic of the Decision Support for the Coastal Network Designer by the Optimization tool in Co.Tr.I.S

\section{THE DESIGN OPTIMIZATION SUBSYSTEM}

\subsection{General Description}

Several methods for coastal transport optimization (Chainas, 2012 \& Giziakis, 2006) and simulation (Darzentas 1996) have been proposed in the literature, but they usually tackle only a small part, or, a reduced version of the complex problem of the Aegean Sea coastal transport system. Many works on coastal network optimization can also be found in the literature, where, the use of evolutionary/heuristic techniques was successful. Most of them try to solve the container ship fleet problems by optimizing cost, consumption, distance traveled and/or delivery deadlines (e.g., Karlaftis, 2009 \& Sun, 2006) and a few also investigate the hub positioning problem or consider environmental issues (e.g., Polat, 2014 \& Windeck, 2013). Evolutionary techniques were found especially capable for the liner shipping problems (e.g., Tsilingiris, 2006 \& Khaled, 2012). Other works combine them with methods from Graph theory or Game theory especially in a search of equilibrium during network design with competing goals (e.g., Dinu, 2011 \& Fagerholt, 2004).

In Co.Tr.I.S the optimization module is designed to solve the complete, complex and multi-objective problem where the user wants to optimize the full scenario and has several goals such as: minimize cost, minimize travel time, maximize ship utilization, maximize demand coverage, maximize passenger satisfaction, minimize fares, minimize effect of weather conditions, maximize schedule accuracy, minimize delays, increase reliability, and their combinations. Co.Tr.I.S interface and the optimization modules aim to help potential users (such as the Ministry, the Maritime companies or the Local Authorities), to select the appropriate system parameters, examine/compare several alternative solutions and finally reach a globally optimal one, based on specific information at hand, and, the restrictions and goals they wish to satisfy.

The high information volume and detail offered by Co.Tr.I.S., the large number of realistic parameters, their complex relationships and the different goals and restrictions posed by all actors involved, create a Non-deterministic Polynomial (NPhard) optimization problem that cannot always be solved within acceptable computer time by exact algorithms. Therefore, the main Optimization Module is based on heuristics/evolutionary techniques i.e. Genetic Algorithms (GA), in order to search only a part of the vast solution space and converge much faster near the optimal solution. (Moussas, 2015).

\subsection{Optimization Methodology \& Objectives}

3.2.1 Multi-stage Optimization: The problem of Coastal Transport System can be seen as a multi-level or multi-stage problem consisting of several interconnected stages such as 1) The Geometry of the network with all the nodes (ports) and their connections. 2) The Routes serviced. The routes \& trips, as well as the sequence of ports per trip, are defined here. 3) The Ship Allocation, Schedule, and Frequency of Service. The frequency of service is defined by the Routes and their corresponding demand. For each route/schedule, the system must assign a ship with the appropriate characteristics. 4) Operational issues. The stage is based on the results of $2 \& 3$. Ship operation issues like speed, port queues, and time windows for arrival/departure or load/unload are defined here, and the results may lead to a ship reallocation at 3 or rescheduling at stage 2 .

The optimization tool in Co.Tr.I.S must be able to face either single stage or multi-stage problems. When facing a simple network problem or the optimization focuses in one of the above stages, the use of a simple optimization technique is usually sufficient to provide the required solution. But, the typical problems that a Co.Tr.I.S user is about to face will cover often all five stages of the large and complex Aegean coastal network, thus, resulting in a multi-level hierarchical 
system. In this case, bi-level optimization (Figure 2) may be required, where, by using game theory techniques equilibrium is reached (e.g. Stackelberg, Nash).

Nested evolutionary algorithms are a popular approach to handle bi-level problems, where lower level optimization problem is solved corresponding to each and every upper-level member (Sinha A. et al., 2017). Nested methods in the area of evolutionary algorithms have been used in primarily two ways. The first approach has been to use an evolutionary algorithm at the upper level and a classical algorithm at the lower level, while the second approach has been to utilize evolutionary algorithms at both levels, as it is also the case in the present work.

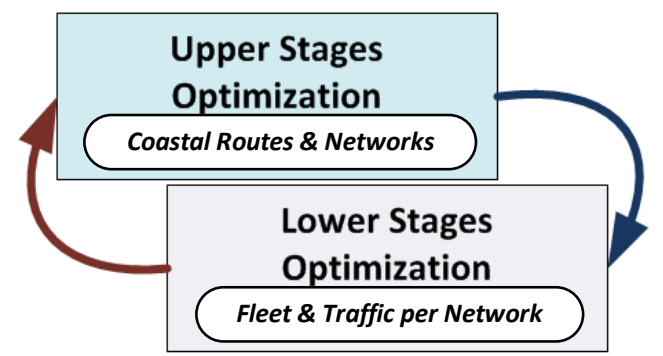

Figure 2: Bi-level optimization for the multi-stage system

\subsubsection{Multi-objective \& Multi-parametric Optimization:}

The existence of several user categories, not sharing the same interests, created the need for custom-made optimization. Each user, stakeholder, authority, or agency has its own priorities, restrictions or preferences. In order to solve this and support all by the same system, an array of weights is introduced in the cost function during the overall $K P I_{u}$ (Key Performance Index per user) calculation from the numerous $(n)$ Performance Indicators $(P I)$. Each user $(u)$ may define a separate set of Weights $\left(w_{u}\right)$ that best represents the user objectives and goals. An indicative \& qualitative weighting per user group is shown in Table 3. Currently, four different KPIs have been designed, corresponding to four different actors i.e., ministry, maritime companies, local authorities, or, passengers. The general calculation form is:

$$
K P I_{u}=\sum_{k=1}^{n} w_{u / k} \cdot P I_{k}
$$

A description of the different objectives/goals of the different users of the system follows: 1) Optimization for the Ministry Optimization of Coastal Transport Network design from the point of view of the Ministry focuses mainly on the Coastal Lines Network full coverage, the existence of a minimum level of connection with every island even if not financially attractive (thin lines), redundancy, safety, high/low season coverage, demand coverage, reasonable tariffs, and less, on the ships used or traffic/schedule specific details. 2) Optimization for the Local Authorities. On the other hand Local Authorities in each island share, of course, similar goals for their island with the Ministry, but they always aim to higher figures than the bare minimum a Ministry would set. Local Authorities desire more redundant connections to other island and the mainland, and they also require larger or faster ships and more frequent schedules, aiming also to maximize the satisfaction of local population and the increase of visitors/tourists. 3) Optimization for the Coastal Lines Maritime Companies. Optimization of Coastal Transport Network design from the point of view of the Maritime Companies is somehow different as they are not willing to serve non-profitable connections especially during low season, they do not redundancy as this also means higher competition, and they focus more on ships and schedules in an attempt to maximize the ship utilization, minimize the ship consumption, travel at full capacity and lower cost, and of course maximize the company profit. 4) Optimization for Travel Agencies \& potential Passengers. Optimization of Coastal Transport Network usage by someone planning a trip is also a different point of view with different goals. First, the travelers do not redesign the network. They select among existing connections, ships and schedules those best serving their needs. What a tourist or a travel agency seeks is to reach the destination as comfortable and cheap as possible, to minimize the travel time or the fare, to reduce any connection delays, to increase connection redundancy and reliability, to simplify longer tours on multiple destinations and of course to satisfy the traveler. 5) Optimization needed for any new and/or urgent connection Demand. A different case of Optimization of Coastal Transport Network comes up when a new connection is required, often urgently due to a sudden demand, and this must be done without redesigning or altering the existing situation. The existing design should optimally incorporate the best connection from a number of candidates, i.e. the one that introduces the minimum disorder and brings the maximum satisfaction of the new data \& restrictions. There are several reasons that may cause such an urgent and unexpected demand e.g: 1) from a sudden high rise of the typical demand for a specific destination not previously forecasted due to a new tourist attraction, 2) from a natural disaster that will force an urgent transport of goods \& people, 3) from a sudden interruption of another line due to accidents, strikes, etc. Especially for the last two cases and or goods transportation, Co.Tr.I.S could support an automatic coastal line creation system with the help of port automation and unmanned surface vehicles.

\begin{tabular}{|l|l|l|l|l|}
\hline $\begin{array}{l}\text { Indicative Line } \\
\text { characteristics }\end{array}$ & \multicolumn{4}{|l|}{$\begin{array}{l}\text { Importance of } \\
\text { depending } \text { on the user objectives }\left(w_{u}\right)\end{array}$} \\
\hline (PIs) & Ministry & Locals & Company & Traveler \\
\hline Demand & High & High & High & Low \\
Distance & Low & High & High & Low \\
No. of Stops & Low & High & Low & High \\
Travel Time & Low & High & Low & High \\
Cost & Low & Low & High & High \\
$\ldots$ & $\ldots$ & $\ldots$ & $\ldots$ & $\ldots$ \\
Thin Lines & High & High & Low & Low \\
\hline
\end{tabular}

Table 3. An indicative weighting of some PIs, when calculating the overall KPI for the cost function for different users.

The PI values are retrieved and/or calculated from the system's database that includes all parameters, variables, and raw data collected, the MVs (Measured Values) \& CVs (Calculated values). An indicative list of the numerous model variables from different sources follows: Island characteristics such as, population, autonomy, hospitals and public services, airports, local population transportation demand, visitors demand, Port characteristics such as, capacity for ships - size and number, infrastructure for refuelling, waste, passenger accommodation, load/unload delays, Connections geographical distance, 
nautical distance, shuttle line or cyclic route, forced route, number of stops, alternative routes, Demand per route passengers, cars, trucks, seasonality, statistics, Schedule frequency of each route, departure, travel time, delays, time windows, bad weather delays, winter/summer adjustments, waiting queues, Ships type, capacity, speed, various costs, various fares, as well as, historical demand statistics \& forecasts, Weather statistics, etc. In addition to the above variables, a large number of constraints is always imposed by the designer. For a coastal transport system under development, an indicative list of typical constraints follows: available fleet (set of ships) and companies, $\min / \max$ capacity per route, $\min / \max$ speed per route, $\max$ wind speed, max over-length, max time per route, max number of stops, min allowed frequency of service, aver/max load/unload delays, aver/max waiting for connections, min demand coverage, min capacity coverage, max number of hubs, etc. For a typical user request several of the above quantities will be fixed (constant value), others will be free to change inside an acceptable range (discrete or continuous) and others will be set/adjusted/restricted by the user.

\subsection{Tools, Software, and Interface}

The implementation of Co.Tr.I.S was based on two well-known platforms/tools, ArcGIS ${ }^{\circledR}$ and MatLab ${ }^{\circledR}$. In this work, the functionality of the design/optimization tool will be presented in detail.

3.3.1 The Co.Tr.I.S Information System: Co.Tr.I.S is developed on the ArcGIS platform and includes several subsystems for: Data retrieval (S1, S2), Statistical analysis (S3), Data visualization (S4), as well as, subsystems with specialized modules for Network generation, Scenario validation (S5), solution Optimization and Decision support (S6), etc. During network design, the user selects the islands/ports of interest and the system prepares a detailed data set that is forwarded to the optimization tool. Several forms are offered to Co.Tr.I.S user, to support the selection/extraction of the necessary data. The data set is prepared in .csv format and contains all available information (MVs, CVs, PIs) regarding the selected islands and/or ports (Figure 4).

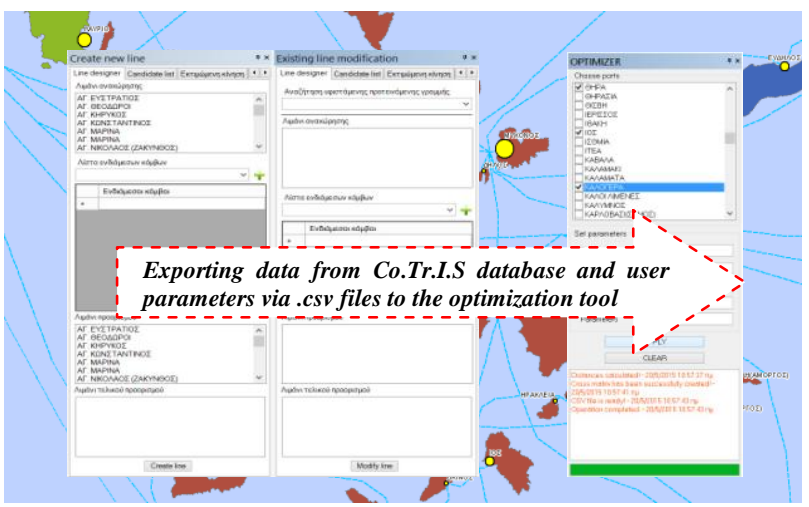

Figure 4. Data extraction for the design/optimization tool.

3.3.2 The Optimization Subsystem: S6 is developed using the MatLab programming environment and it is invoked by the Co.Tr.I.S user after preparing the case data. The tool receives all necessary information from the database via a .csv data file. In addition, the optimization tool requires from the user to enter some more parameters or data regarding the methods/algorithms applied (iterations, detail level, convergence, etc.), as well as, its objectives/goals and the corresponding weighting coefficients in Equation (1), $w_{u}$. The network design \& optimization is performed in 4 main stages named OPT-1 to OPT-4 (Figure 5):

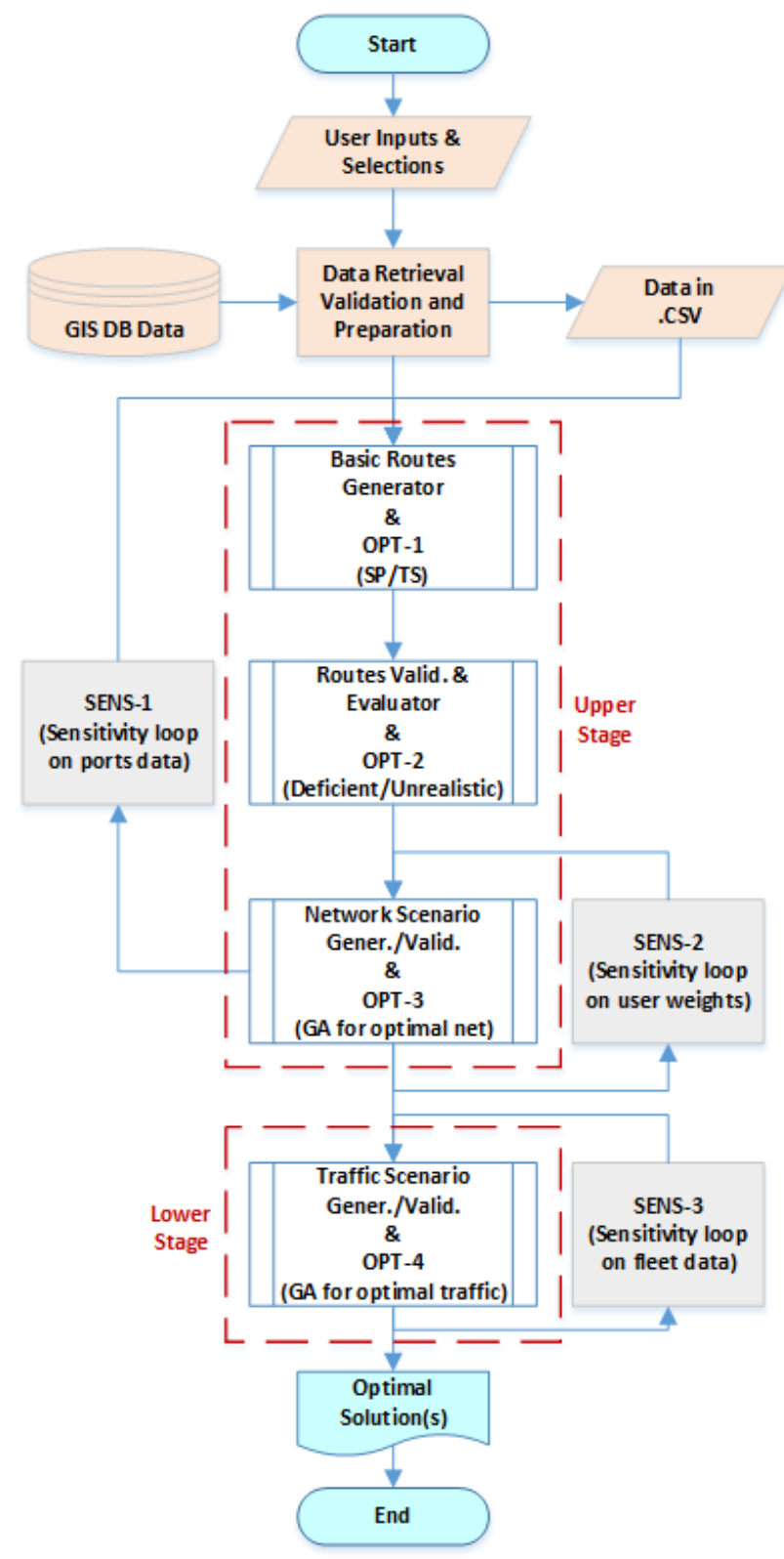

Figure 5. Co.Tr.I.S Design/Optimization Work Flow.

Stage-1: After selecting the ports of interest, all possible port connections are created (basic routes Generator), either $\mathrm{p} 2 \mathrm{p}$ or with more stops, round trips or circular connections. A first optimization (OPT-1) is performed at this stage, based on the shortest path \& traveling salesman methods, to select the best among several compatible routes serving the same ports.

Stage-2: An evaluation of the basic routes is then calculated (basic routes Evaluator, based on their PIs/KPIs, e.g., demand, distance, time, overall efficiency, etc.). At this stage, the routes are sorted by deficiency and, for each port, the most deficient lines are discarded (OPT-2), provided that the port is still served by a minimum number of lines set by the user. 
Stage-3: All basic routes survived after stage-2 are then combined to create all possible coastal network scenarios (scenarios Generator) that may serve the area under consideration. The resulted scenarios are validated and evaluated and the optimal one (OPT-3) or the top-10 best are returned to the user. The extremely high number of combinations and resulted scenarios do not permit the exhaustive search of all possible solutions. Therefore, the optimization task is performed by Genetic Algorithms (GA). The GA requires only a subset of the search space to start searching for the optimal solution. The user may also adjust the GA parameters (e.g. initial population, generations, etc.) in order to improve its performance.

Stage-4: From the available fleet data and the relative user selections, all possible traffic scenarios are created for the optimal network. The traffic scenarios are validated and evaluated and the optimal one (OPT-4) is returned to the user. If more than one network scenarios are investigated, stage- 4 is repeated for all of them. Again here the optimization task is performed by Genetic Algorithms (GA) as in stage-3. A flowchart of the above workflow follows (Figure 5).

All optimization results are also subjected to sensitivity analysis regarding smaller or larger variations of the usersupplied data or the retrieved statistical/calculated data. There are three (3) sensitivity analysis loops in the tool: 1) SENS-1 performs sensitivity analysis on the user supplied and database data on the port characteristics and demand details, 2) SENS-2 performs sensitivity analysis on the user preferences weighting factors, both of them affecting the optimal solution for the network implementation, and, 3) SENS-3 performs a sensitivity analysis on the fleet and traffic data that affect the optimal solution for the traffic implementation.

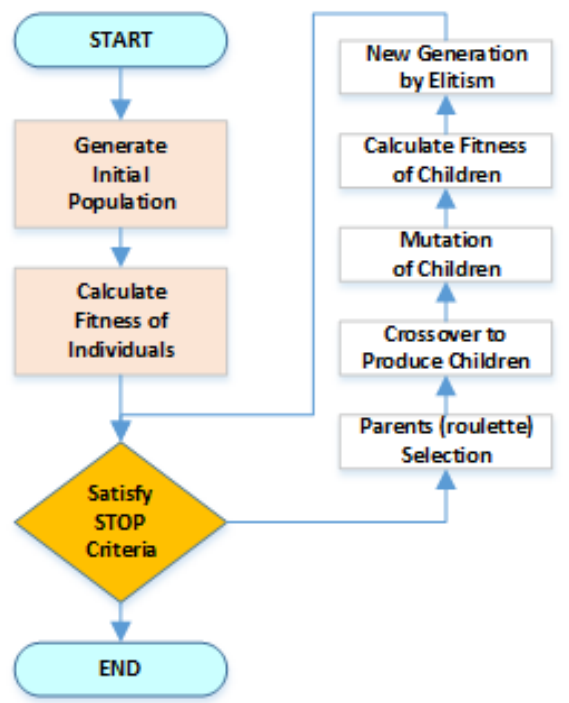

Figure 6. Co.Tr.I.S GAs general flowchart

The Co.Tr.I.S GA tools are based on the classic implementation of a Genetic Algorithm shown in Figure 6, a chromosome containing all MV \& CV quantities and a fitness (cost) functions based on the user's KPI (see Appendix).

GA fitness (cost) function design is not trivial for the Coastal Transport Network design. Experience may also help optimization because it may define virtual costs associated with subjective characteristics of the solution that will tend to favor solutions with the prescribed valuable characteristics. In the Co.Tr.I.S case, the cost functions take into consideration the objective costs associated with travel distance \& time of each vehicle of the fleet, capacity/demand coverage, etc., but they also include virtual costs associated to violation of constraints as maximum capacity, maximum duration, maximum number of stops in a route, etc. In addition, legal or social constraints, as well as QoS (Quality of Service), must also be transformed in virtual costs to properly guide the optimization process to a satisfactory solution in collaboration with each user category.

\subsection{Case study}

A sample of the Aegean islands was selected to demonstrate design and optimization phase as it is supported by the Co.Tr.I.S tools. The case study is from the Cyclades area and the sample includes seven (7) Aegean islands (Syros, Tinos, Mykonos, Paros, Naxos, Ios \& Amorgos), and, one (1) mainland port (Piraeus). Co.Tr.I.S extracts from the ArcGIS database all relevant data and prepares them for the design \& optimization tool. A sample of all potential connections is shown in Figure 7. The optimal coastal network should contain only those that best support the user goals \& preferences.

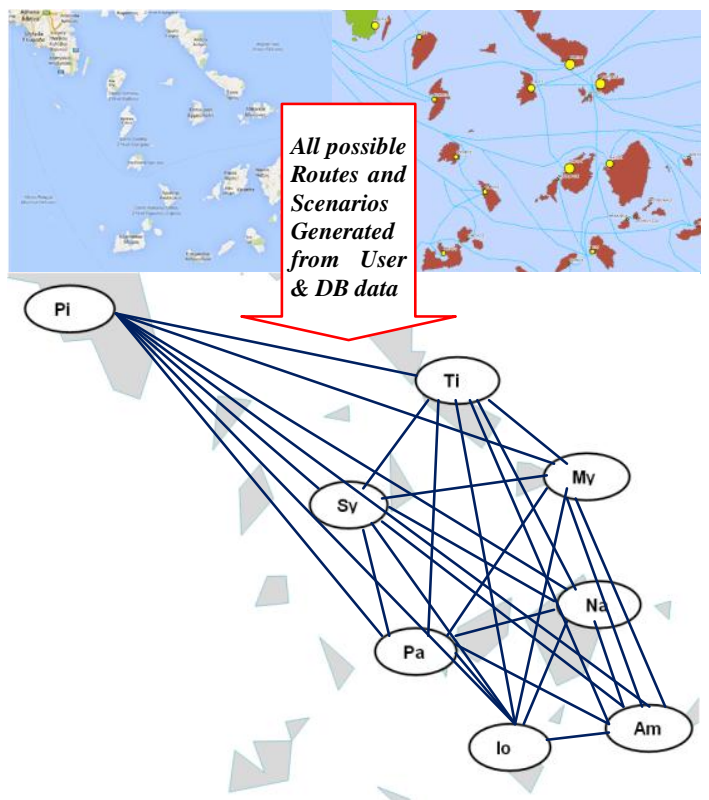

Figure 7. Based on user's selections, geo \& traffic data are collected to generate all possible routes \& scenarios for each case under consideration.

Two potential user categories of the system were considered for this case study:

1) User A represents a maritime company and its main objectives are to minimize the number of ships in the network, the total distance traveled and their consumption, and also to maximize the ships' utilization.

2) User B represents the local authorities or local population and their main objectives are to minimize the travel time, increase the routes' redundancy and reliability, and also maximize the visitors \& population convenience \& satisfaction. 


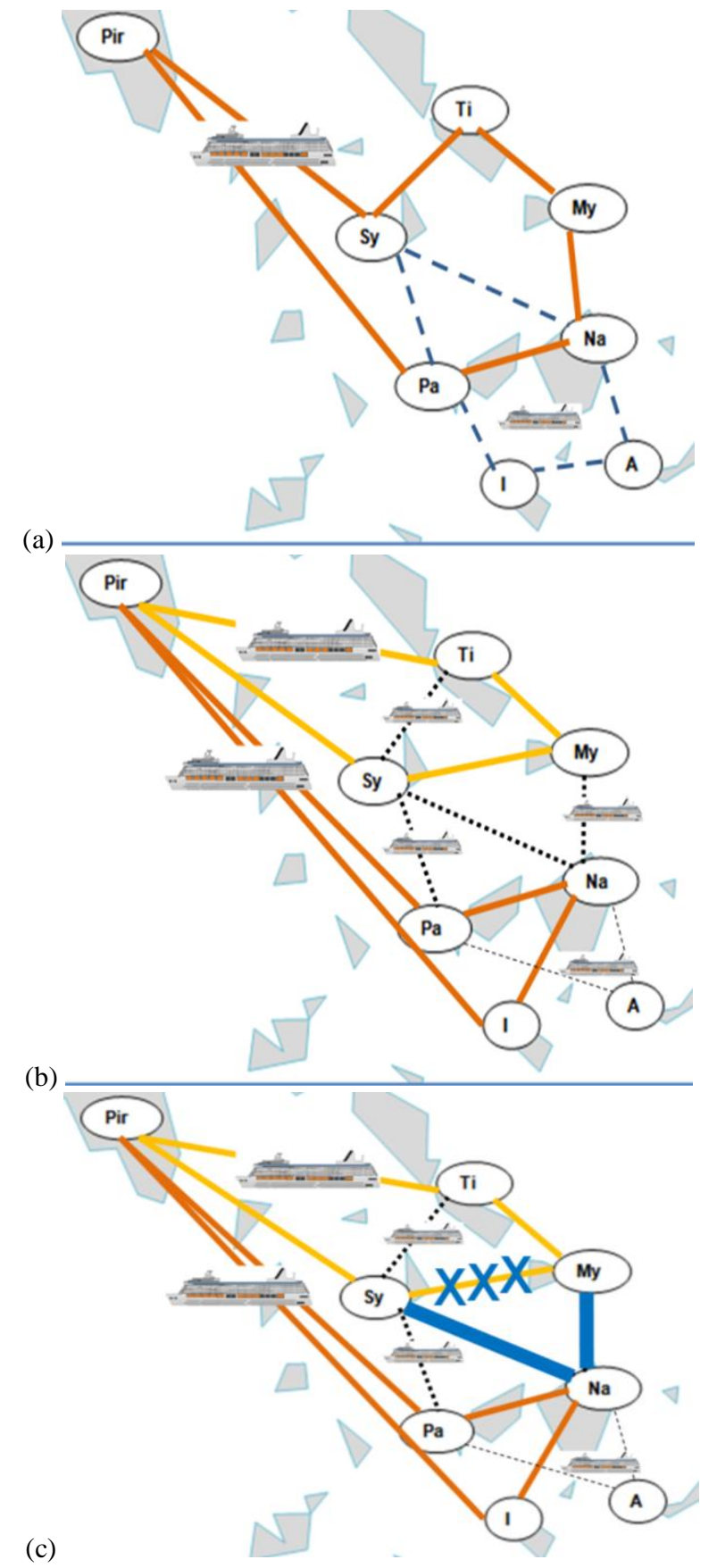

Figure 8. Co.Tr.I.S solutions: (a) for User A preferences (b) for

User B preferences (c) for the new Case C of User B.

The tool was called twice using a different set of weights $w_{u}$ for each user category. The weighting coefficients for User A penalized the longer distances, the high number of ships, the higher speed/consumption and the unutilized capacity of the fleet. The results for User A suggested to implement only two circular routes, a larger one from the mainland (Piraeus) and a smaller one in the Cyclades, and with a traffic frequency of only three (3) trips per week each (Figure 8a) (Moussas et al. 2015).

On the other hand, the weighting coefficients for User B penalized the slow connections with many stops, the fewer ships - lack of redundancy, the lower speed, and the underserved demand. The results for User B suggested to implement four (4) routes, two larger and circular from the mainland (Piraeus) and two radial routes from local Hub(s), and all with higher traffic frequencies of up to 7 trips per week (Figure 8b) (Moussas et al. 2015).

3) New Case C. In this case study we further considered a new sudden and high-level demand for transport between the port of Piraeus and the island of Naxos handled by User B. The preferences remain the same but the demand data change and Co.Tr.I.S produces a different coastal network by extending the upper circular route to also cover the island of Naxos. This connection also cancels the need for a $\mathrm{p} 2 \mathrm{p}$ connection between Syros \& Mykonos (Figure 8c).

\section{SMART ISLANDS \& CO.TR.I.S}

The particularities of the "smartification" of an island are related to its geographic characteristics, the isolation, the coastal lines, the tourism, the medical care \& emergency transport, the infrastructure, the transport of goods, the education, the limited economic possibilities, etc. We note here that an island constitutes an autonomous entity that must be seen and considered in a holistic way. Its "smartification" should not concern just a city or a village but the entire island.

The coastal connection of Cyclades with Athens/Piraeus and other cities in the mainland as well as with other islands in the Aegean is still an acute problem. Under the frame of a smart sustainable, holistic \& integrated coastal transport system, the Co.Tr.I.S tools can offer a number of solutions for the "smartification" of the islands from the mobility and connectivity point of view.

The operational use of the system is still lacking financial resources from the involved authorities. Nevertheless, the improvement of the system with the support of the local municipalities makes Co.Tr.I.S one of the most advanced smart applications in the key enabling factor of "transport".

Many of the emerging "smart" technologies proposed for the development of islands may also contribute to better Co.Tr.I.S functionality. Some examples are:

- Smart data collection/retrieval applications and big data analytics will provide Co.Tr.I.S with better more accurate and updated information in its database.

- The implementation of port automation technologies will reduce the port delays and improve the ships correspondence.

- The creation of smart floating terminals outside of congested ports will improve the coastal route efficiency.

- The introduction of unmanned surface vehicles can improve the port efficiency and reduce the load/unload delays.

- The introduction of new connections to transport goods, especially in emergencies, could be also supported by USVs and automated ports. A 'smart' module can establish new routes on demand by collecting requests from a network service and automatically allocating routes for unmanned ships to fully automated ports in order to transport the specific goods/containers. 
In general, a Coastal Transport Information System will play a critical role on the "smartification" of islands because a large percentage of island improvements are based on the island's smarter \& greener connections, people's mobility and goods transportations. Co.Tr.I.S can successfully handle all of them and therefore contribute significantly towards smarter and sustainable islands.

\section{CONCLUSIONS \& PERSPECTIVES}

The functionality of the Co.Tr.I.S system was summarily presented, and especially the network design and optimization subsystem with its various optimization stages, the algorithm implementations and its potentiality to propose a better network design, based on its user preferences. In Co.Tr.I.S, optimization is performed using GAs which overcome the time \& computation problems of classic and exhaustive methods, caused by the high number of Aegean islands and the route combination scenarios. In addition to its main coastal network design functionality, the system may equally be used for the optimal use \& exploitation of an existing coastal network by e.g. tourists \& travel agencies to create new types of trips \& tours, thus offering a valuable tool to a very large user category. A sample case study was presented to show its smartness \& adaptability to each user needs, and also a discussion on how it could be complemented by the emerging smart technologies for smarter islands. Co.Tr.I.S seems also able to contribute significantly to the sustainable "smartification" of the Aegean islands provided its adoption from the relevant authorities and users, as it offers custommade optimization for the coastal transportation problem leading to a smarter use of resources and improved connections $\&$ mobility for the islands.

\section{REFERENCES}

Albino V., Berardi U. and Dangelico R. M., 2015. Smart Cities: Definitions, Dimensions, Performance, and Initiatives, Journal of Urban Technology, 22(1), pp. 3-21, DOI: 10.1080/10630732.2014.942092.

Chainas, K., 2012. The Optimization of The Greek Coastal Shipping Transportation Network. Tourismos: An International Multidisciplinary Journal Of Tourism, Volume 7, Number 1, Spring-Summer 2012, pp. 351-366.

Darzentas, J. and Spyrou, T., 1996. Ferry Traffic in the Aegean Islands: A Simulation Study. Journal of the Operational Research Society, Vol. 47, No. 2 (Feb., 1996), pp. 203-216.

Dinu, S., and Odagescu, I., Research on an Optimization Model for Transportation Network Design, (February 12, 2011). Available at SSRN: http://ssrn.com/abstract $=1760663$ or http://dx.doi.org/10.2139/ssrn.1760663.

Fagerholt, K., 2004. Designing optimal routes in a liner shipping problem, Maritime Policy and Management, 31: 4, 259-268.

GISIG, Geographical Information Systems International Group, 2014. Smart Webservices for Mediterranean Islands, ICT-PSP Grant 2011-14, http://www.gisig.eu/smart-islands-2/ (30 Apr
2018).

Giziakis, K., Paravantis, J.A., Michalochrista, M. and Tsapara, A., 2006. Optimal Operation Of Passenger Shipping In The Aegean. In: International Conference "Shipping in the era of Social Responsibility” Argostoli, Cephalonia, Greece, 14-16 September 2006.

Karlaftis, M. G., Kepaptsoglou, K., and Sambracos, E., 2009. Containership routing with time deadlines and simultaneous deliveries and pick-ups, Transportation Research, Part E 45(1), pp. 210-221.

Khaled Al-Hamad, Mohamed Al-Ibrahim and Eiman Al-Enezy, A. 2012. Genetic Algorithm for Ship Routing and Scheduling Problem with Time Window. American Journal of Operations Research, 2012, 2, 417-429.

Manville, C., Cochrane G., et al., 2014. Mapping Smart Cities in the EU. Study IP/A/ITRE/ST/2013-02 PE 507.480, DG for Internal Policies, Policy Department A: Economic and Scientific Policy, European Union, Brussels. DOI: $10.2861 / 3408$.

Moussas, V., Pantazis, D. N., Stratakis, P., 2015, Modeling Methodologies for Optimization and Decision Support on Coastal Transport Information System (Co.Tr.I.S), WASET, International Journal of Geological and Environmental Engineering Vol:9, No:5, p:1066-1070.

Pantazis, D. N., Moussas, V. C., Murgante, B., Daverona, A. Stratakis, C., P., Vlissidis, N., Kavadias, A., Economou, D., Santimpantakis, K., Karathanasis, B., Kyriakopoulou, V., and Gadolou, E., 2017. Smart Sustainable Islands vs. Smart Sustainable Cities. ISPRS Ann. Photogramm. Remote Sens. Spatial Inf. Sci., IV-4/W3, 45-53, doi.org/10.5194/isprs-annalsIV-4-W3-45-2017.

Pantazis, D.N., Stratakis, P. Karathanasis, C. Gkadolou, E., 2013. Design of a Coastal Transport Integrated System: Preliminary System Specifications and Data Collection for the Aegean Sea Islands. In: B. Murgante et al. (Eds.): ICCSA 2013, Part IV, LNCS 7974, pp. 268-283, CSpringer-Verlag Berlin Heidelberg.

Polat, O., Gunther, H-O ad Kulak, O., 2014. The feeder network design problem: Application to container services in the Black Sea region, Macmillan Publishers Ltd. 1479-293, Maritime Economics and Logistics, Vol. 16, 3, pp. 343-369.

Sinha, A., Malo, P., Deb, K., 2017. A Review on Bilevel Optimization: From Classical to Evolutionary Approaches and Applications. arXiv:1705.06270v1 [math.OC].

Sun, X., and Li, N., 2006. A new immune genetic algorithm for the large scale ship routing problems. In: the International Conference on Management of Logistics and Supply Chain Chang Sha/Chine, Sydney, Australia.

Tsilingiris, P. and Psaraftis, H., 2006. A Multi-Stage Optimization-Based Approach for the Liner Shipping Problem, In: 3rd International Congress on Transportation Research in Greece, Thessaloniki, Greece, May. 
Windeck, V., 2013. A Liner Shipping Network Design: Routing and Scheduling Considering Environmental Influences. Wiesbaden, Germany: Produktion und Logistik, Springer Gabler.

Winters J.V., 2011. Why are Smart Cities Growing? Who moves and who stays? Journal of Regional Science, 51(2), pp 253-270.

\section{APPENDIX}

The appendix presents additional supporting details/figures on the GA structure that were not put in the main text, namely, the structure of the GA chromosome structure and the calculation of the overall score (Figure 9).

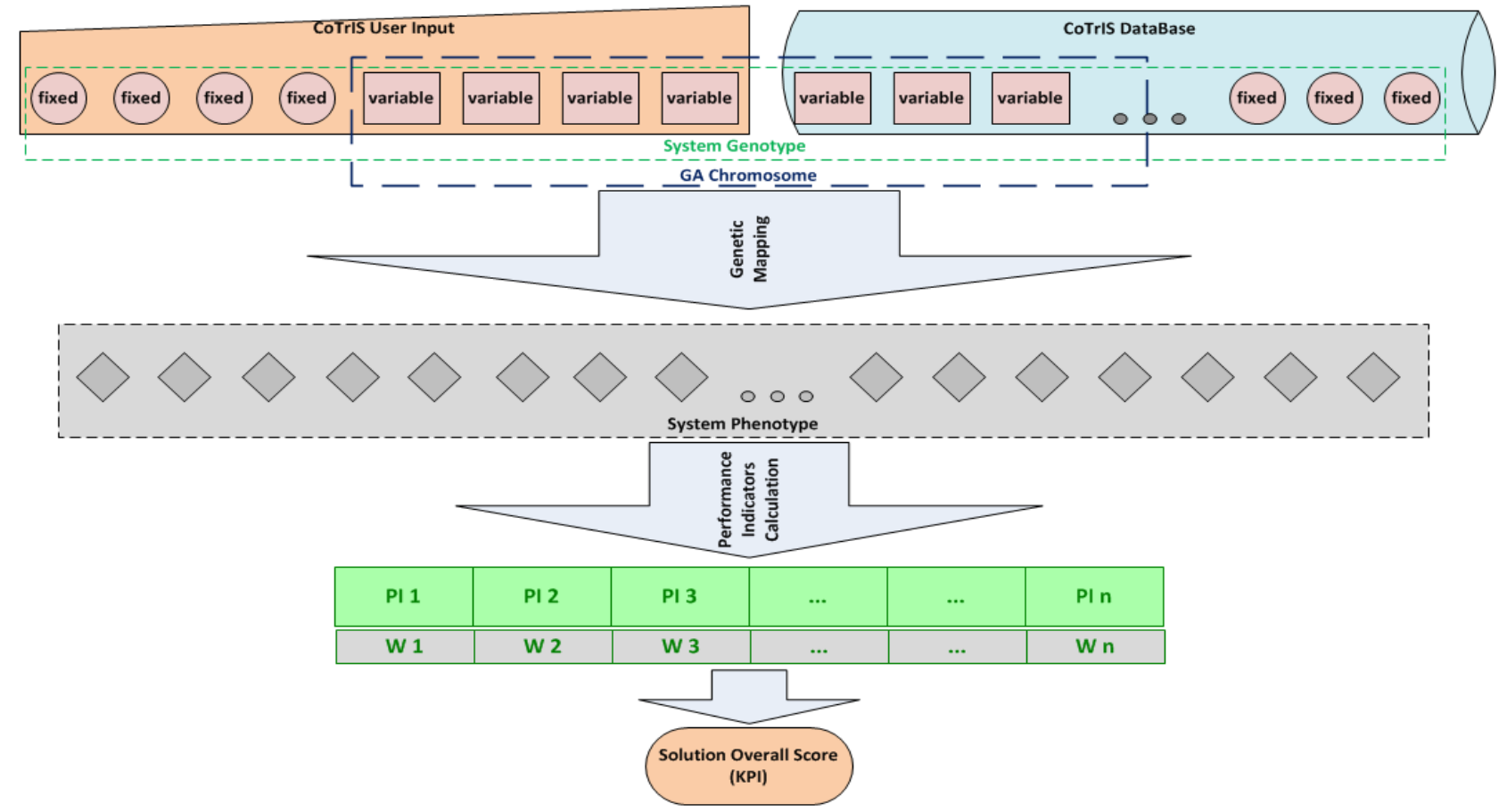

Figure 9. GA Chromosome (Genotype - Phenotype) \& Overall Score 